\title{
Self Esteem and Well Being among University Going Adolescents: A Gender Perspective
}

\author{
Urvashi $^{1 *}$, Prashant Srivastava ${ }^{2}$
}

\section{ABSTRACT}

Background: Adolescence is clearly a distinct and change related time in the context of life satisfaction, due to the multitude of biological, psychological, social, and cognitive changes occurring during this phase and global self-esteem may act as an indicator of how adolescents face and manage these challenges, which further may effect on adolescents' life satisfaction. Healthy self-esteem is the experience of being competent to cope with the basic challenges of life, stress and being worthy of happiness. Many psychological problems such as depression and suicide occur as a result of low self-esteem and confidence. Aims \& Objectives: To assess and compare gender differences among university going adolescents in terms of self-esteem and well-being. Method: 100 university going adolescents (50 male respondents \& 50 female respondents) have been included purposively in the study. Semi- Structured Socio Demographic datasheet was used to collect the relevant socio demographic information followed by Rosenberg Self Esteem Scale and PGI General Well Being Measure. Data collected was analyzed using Statistical Package for Social Sciences (SPSS- 20 version). Result: The study findings highlights significant gender differences among university going adolescents in terms of self-esteem and well-being. Result found that female university going adolescents has less self-esteem and wellbeing as compared to their male counterparts.

\section{Keywords: Self-esteem, Well-Being, Adolescents and Gender Perspective}

Adolescence can be specifically turbulent as well as a dynamic period of one's life. Adolescent moral development has been conceptualized in three phases (i.e., pre-conventional morality, conventional morality, and post-conventional morality) by (Kohlberg, 1978). Gilligan (1993) advanced understanding by exploring observed gender differences in how boys and girls approach moral dilemmas, demonstrating that generally, boys seek direct resolution and girls

\footnotetext{
${ }_{1}^{1}$ Assistant Professor, Dept. of Social Work, Chatrapati Sahuji Maharaj University, Kanpur, India

${ }^{2}$ Psychiatric Social Worker, Dept. of Pediatrics, Child Development Centre, Maulana Azad Medical College and Associated Lok Nayak Hospital and Ph.D. Scholar, Dept. of Social Work, Jamia Millia Islamia, New Delhi, India *Responding Author
}

Received: December 30, 2016; Revision Received: January 20, 2017; Accepted: January 30, 2017

(C) 2017 Urvashi, Srivastava P; licensee IJIP. This is an Open Access Research distributed under the terms of the Creative Commons Attribution License (www.creativecommons.org/licenses/by/2.0), which permits unrestricted use, distribution, and reproduction in any Medium, provided the original work is properly cited. 


\section{Self Esteem and Well Being among University Going Adolescents: A Gender Perspective}

will avoid conflict to maintain a relationship (Rew, 2005). Adolescence is a transitional period and it is the bridge between childhood and adulthood. It is the time of rapid development of growing to sexual maturity, discovering one's real self, defining personal value and finding one's vocational and social direction. Age of adolescence is age of identity formation where occupational, educational and personal contexts develop.

Adolescence is clearly a distinct and change related time in the context of life satisfaction, due to the multitude of biological, psychological, social, and cognitive changes occurring during this phase (Proctor et. al., 2009 \& Goldbeck et. al., 2007) and global self-esteem may act as an indicator of how adolescents face and manage these challenges, which further may effect on adolescents' life satisfaction.

Being in India one understands how important gender plays in their daily lives. Usually men are considered to be the higher authority and most of the time they are being obeyed. Even when a child is born, gender is the first thing that is looked at. If it's a boy everyone is usually elated, but if it's a girl then a little disappointed. But in today's context a lot of Indians are opening up and trying to get rid of the evil gender differences. Wilburn and Smith (2005) found in his study "Stress, Self Esteem and Suicidal Ideation in Late Adolescents". Sample. The Life Experience Survey, the Rosenberg Self-Esteem Scale and the Suicidal Ideation Questionnaire were used for the study. The results revealed that both stress and self-esteem were significantly related to suicidal ideation and low self esteem and stressful life events significantly predict suicidal ideation.

According to Diener \& Diener (1995) both self-esteem and life satisfaction indicate one's global evaluations, yet the direction of these evaluations is different (Civitci \& Civitci, 2009). Selfesteem reflects an individual's perceptions and evaluations of himself or herself, whereas life satisfaction involves the individual's evaluation of one's life as a whole including different areas of life such as school, family, and friends as well as oneself (Civitci \& Civitci, 2009).

\section{MATERIAL \& METHODS}

Aim:

1. To assess and compare the gender difference among university going adolescent in terms of self-esteem and well-being.

\section{Universe of the study:}

Adolescents of Chatrapati Sahuji Maharaj University, Kanpur were constituted as universe of the study as aim of the present study was to assess and compare the gender difference among university going adolescent in terms of Self-esteem and Well-Being. 


\section{Hypothesis:}

2. There will be no significant gender difference among self-esteem and well-being among university going adolescents.

\section{Sample:}

The sample comprised of 100 adolescents who met the inclusion and exclusion criteria. Samples were further divided into 50 male adolescents and 50 female adolescents. These samples were selected using purposive sampling technique.

\section{Tools Used For Assessment:}

- Socio Demographic Data Sheet.

- Rosenberg Self Esteem (Rosenberg, 1965)

- $\quad$ PGI General Well Being Measure (Verma and Verma, 1989)

\section{Statistical Analysis:}

For the statistical analysis SPSS (Statistical Package for Social Sciences) 20.0 version was used. Frequencies, Chi Squared test, $\mathrm{T}$ test were used in the current study.

\section{RESULTS}

Table 1.: Comparison of Socio-Demographic Characteristics of male and female university going adolescents

\begin{tabular}{|c|c|c|c|c|c|c|}
\hline Variables & Level & $\begin{array}{l}\text { Male } \\
(\mathrm{N}=50)\end{array}$ & $\begin{array}{l}\text { Female } \\
(\mathrm{N}=50)\end{array}$ & $x^{2}$ & Df & $\mathbf{P}$ \\
\hline \multirow[t]{2}{*}{ Family Type } & Nuclear & 25 & 31 & \multirow[t]{2}{*}{1.961} & \multirow[t]{2}{*}{1} & \multirow[t]{2}{*}{.227} \\
\hline & Joint & 25 & 19 & & & \\
\hline \multirow[t]{2}{*}{ Domicile } & Rural & 41 & 38 & \multirow[t]{2}{*}{.101} & \multirow[t]{2}{*}{1} & \multirow[t]{2}{*}{.750} \\
\hline & Urban & 09 & 12 & & & \\
\hline \multirow[t]{3}{*}{ Category } & General & 20 & 15 & \multirow[t]{3}{*}{1.128} & \multirow[t]{3}{*}{2} & \multirow[t]{3}{*}{.561} \\
\hline & $\mathrm{OBC}$ & 22 & 25 & & & \\
\hline & SC/ST & 08 & 10 & & & \\
\hline \multirow[t]{4}{*}{ Religion } & Hindu & 17 & 19 & \multirow[t]{4}{*}{.407} & \multirow[t]{4}{*}{3} & \multirow[t]{4}{*}{.929} \\
\hline & Muslim & 11 & 09 & & & \\
\hline & Christian & 08 & 09 & & & \\
\hline & Others & 14 & 13 & & & \\
\hline
\end{tabular}

Table shows descriptive information about the socio- demographic characteristics of the respondents which were divided into two groups as male university going adolescent group and female university going adolescent group. The result shows that there is equal respondents in male group belongs to nuclear and joint family type but in female group majority of respondents belongs to nuclear family type. Study finding shows that majority of male and female respondents belong to rural background. Study finding reveals that majority of male and female

(C) The International Journal of Indian Psychology, ISSN 2348-5396 (e)| ISSN: 2349-3429 (p) | 116 
respondents belong to OBC category. Table shows that majority of male and female respondents belongs to Hindu religion. Result shows no statistically significant difference was found between both the study groups.

Table 2.: Comparison of male and female university going adolescents in terms of Self-esteem and Well-Being

\begin{tabular}{|c|c|c|c|c|}
\hline \multirow{2}{*}{ Variables } & \multicolumn{2}{|c|}{ Group } & \multirow{2}{*}{ 't' value } & \multirow{2}{*}{ Df } \\
\cline { 2 - 3 } & \multicolumn{2}{|c|}{ Obtained M+SD Score } & & \\
\cline { 2 - 3 } Self Esteem & $21.32 \pm 2.82$ & $19.44 \pm 4.19$ & 2.631 & $.010^{*}$ \\
\hline Well-Being & $14.60 \pm 4.57$ & $12.18 \pm 4.43$ & 2.687 & $.008^{*}$ \\
\hline
\end{tabular}

* Significant at 0.01 level

Table 2 suggests that in self-esteem and well-being, the mean score of male respondents was found high than female respondents which suggest that self-esteem and well-being was high among the male respondents in comparison to female respondents, the $t$ value computed for this was found to be statistically significant 0.01 level. It indicates that there was significant differences exist among both the respondents in terms of self-esteem and well-being.

\section{DISCUSSION}

One hundred adolescents (50 male university going adolescents and 50 female university going adolescents) were focus of the present study and the aim was to assess and compare the gender difference among university going adolescent in terms of self-esteem and well-being. The samples were collected from Chatrapati Sahuji Maharaj University, Kanpur. The main tools administered were socio-demographic data sheet, Rosenberg self-esteem scale and PGI General Well Being Measure. The samples of both groups were matched with the variables like family type, domicile, category and religion.

The analysis suggests that in self-esteem, the mean score of male respondents $(21.32 \pm 2.82)$ was found high than female respondents $(19.44 \pm$ 4.19) which suggest that self-esteem was high among the male respondents in comparison to female respondents, the t value computed for this was found to be statistically significant 0.01 level. It indicates that there was significant differences exist among both the respondents in terms of self-esteem.

Present study are in agreement with the study conducted by Iram and Junaid (2011) conducted a research to assess the relationship between Emotional Intelligence and self-esteem. The results showed that emotional intelligence and self-esteem were positively correlated and significant. Females were emotionally intelligent than males as $\mathrm{p}<0.05$ and males showed high self-esteem than females. 


\section{Self Esteem and Well Being among University Going Adolescents: A Gender Perspective}

However revealed that in well-being the mean score of male respondents $(14.60 \pm 4.57)$ was found high than female respondents $(12.18 \pm 4.43)$. The t value computed for this was found to be statistically significant at 0.01 level. It indicates that significant differences exist among both respondents in terms of well-being. So the current study reveals that the male respondents found more well-being in comparison to female respondents.

\section{LIMITATIONS}

Being a time bound study only a small sample could be taken and hence the generalization of the result remains doubtful. If other siblings would have also been included as respondents along with faculty members, it would have been a more accurate study to identify other problems among adolescents.

\section{FUTURE DIRECTION AND IMPLICATIONS}

Based on present study findings it is very clear that there are significant gender differences found among university going adolescents in terms of self-esteem and well-being. With these findings it would be interesting to see the other contributing psycho-social factors such as academic achievement, emotional intelligence, etc. Based on the present study finding psycho-social intervention program can be developed to enhance the self-esteem, well-being and level of confidence of adolescents and its efficacy and feasibility can be assessed.

\section{CONCLUSION}

Present study was conducted to assess and compare the gender difference among university going adolescent in terms of self-esteem and well-being. The study findings highlights significant gender differences among university going adolescents in terms of self-esteem and well-being.

The present study supports the theoretical and empirical understanding of self-esteem as strongly and positively related to well-being. With the help of present study findings adolescents can recognize what is causing them stress and learn how to manage their stress in a healthy and productive manner. It was also proved that Self-esteem has been found to be an important factor for retaining psychological health and well-being as well as positive functioning during adolescence. It may not only benefit the adolescents, but may also help to enhance their academic performance too. Thus the findings of the present study will help adolescents as how to increase self-esteem and well-being in their future life.

\section{Acknowledgments}

The author appreciates all those who participated in the study and helped to facilitate the research process.

Conflict of Interests: The author declared no conflict of interests. 


\section{REFERENCES}

Civitci, N., \& Civitci, A. (2009). Self-esteem as mediator and moderator of the relationship between loneliness and life satisfaction in adolescents. Personality and Individual Differences, 47, 954-958.

Diener, E., \& Diener, M. (1995). Cross-cultural correlates of life satisfaction and self-esteem. Journal of Personality and Social Psychology, 68, 653-663.

Gilligan, C. (1988). In a different voice. Cambridge, MA: Harvard University Press.

Goldbeck, L., Schmitz, T. G., Besier, T., Herschbach, P., \& Henrich, G. (2007). Life satisfaction decreases during adolescence. Quality of Life Research, 16, 969-979.

Iram A., \& Junaid, U. H. (2011). A Relationship between Emotional Intelligence and SelfEsteem: study in universities of Pakistan. Arts and Design Studies.

Kohlberg, L. (1978). Revisions in the theory and practice of moral development. New Directions for Child Development; 2, 83-88.

Pavot, W., \& Diener, E. (2008). The satisfaction with life scale and the emerging construct of life satisfaction. The Journal of Positive Psychology, 3, 137-152. 5.

Proctor, C. L., Linley, P. A., \& Maltby, J. (2009). Youth life satisfaction: A review of the literature. Journal of Happiness Studies, 10, 583-630.

Rew, L. (2005). Adolescent health a multidisciplinary approach to theory, research, and intervention. Thousand Oaks, CA: Sage.

Rosenberg, M. (1965). Society and the Adolescent Self-image. Princeton, NJ: Princeton University Press.

Verma, S. K., \& Verma, A. (1989). Manual for PGI general well-being measure. Lucknow: Ankur Psychological Agency.

Wilburn, V.R., \& Smith, D. E. (2005). Stress, self-esteem and suicidal ideation in late adolescents. Adolescence, 40(157), 33-43.

How to cite this article: Urvashi, Srivastava P (2017), Self Esteem and Well Being among University Going Adolescents: A Gender Perspective, International Journal of Indian Psychology, Volume 4, Issue 2, No. 86, ISSN:2348-5396 (e), ISSN:2349-3429 (p), DIP:18.01.034/20170402, ISBN:978-1-365-68609-2 